\title{
APPLICATION OF ANALYTICAL HIERARCHY PROCESS (AHP) MODEL TO DETERMINE PATIENTS PERCEPTION TOWARDS SERVICE QUALITY OF PUBLIC HOSPITALS IN NIGERIA
}

\author{
Emmanuel Olateju Oyatoye* \\ Department of Business Administration, \\ University of Lagos, Nigeria. \\ E-mail: eoyatoye@unilag.edu.ng \\ Bilqis Bolanle Amole \\ Department of Business Administration, \\ University of Lagos, Nigeria. \\ E-mail:amolebb@yahoo.com \\ Sulaimon Olanrewaju Adebiyi \\ Department of Economics and Financial Studies, \\ Federal University of Agriculture, Abeokuta, Ogun State, Nigeria. \\ E-mail: lanre18april@gmail.com
}

\begin{abstract}
Patients nowadays are more aware and more quality conscious than before as they stands to reason that a high level of quality can translate into patient satisfaction and this is important for an health care providers as they deal with life. This recognition by both the service provider and service receivers made government to establish units of service commission (SERVICOM) in each of the government agency including hospitals in Nigeria to monitor the level of quality of service delivery. However, to what extent does patients' perceptions about health services seem to have been largely recognized in the recent years by health care providers despite the (SERVICOM) unit? This led us to determine the perception of patients towards service quality delivery of public hospitals in Nigeria with the help of analytical hierarchy process (AHP) model to assess and prioritize the generic dimensions or factors for measuring service quality from the perspective of the patients. Questionnaire was formulated in an AHP format and distributed among the two hundred patients of the two public hospitals and responses obtained from them were analyzed accordingly. The findings indicate that the dimensions significantly affect the patients' satisfaction. More specifically, among the five perceived service quality dimensions, tangibles dimension is the least satisfied one. Of particular interest is the attitude of medical Doctors and Nurses to patients' care and duty. However, service charges dimension was the most satisfying one as it cannot be compare to the high charges of private hospitals of comparable status. Thus, this study has implication for decisions on effective monitoring of the entire health system towards enhancing quality service delivery that will increase patient satisfaction which is the mission for establishing hospitals.
\end{abstract}

Keywords: Service quality, patient perception, analytical hierarchy process (AHP), healthcare.

\section{Introduction}

Patient satisfaction and service quality is becoming a critical objective in the strategic planning process. Patients demand more information than ever and do not hesitate to switch to another health care provider if they do not obtain satisfaction (Ramsaran-Fowdar, 2008). As a result, the provision of quality service and improving patient satisfaction are key strategies and are crucial to the long-run success and profitability of health care providers (Gilbert, Lumpkin \& Dant, 1992). 
Patients' perception of health care has gained increasing attention over the past 20 years (Sitzia \& Wood, 1997). It is currently admitted that patients' opinion should supplement the usual indicators of quality in health care (Donabedian, 1988; Cleary, McNei, 1988). Patient expression is an important source of information in screening for problems and developing an effective plan of action for quality improvement in health care organizations (Levine, Plume \& Nelson 1997).

Servqual model is a widely used model in measuring service quality. Considering this model, the evaluation of customer satisfaction (patient satisfaction) level is obtained by discrepancy or gap measures between customers'(patients) expectations, " $P$ ", and their perceptions, " $E$ ", that is. Gap = $P$ - E (Parasuraman, Zeithami \& Berry 1985). Therefore, customer's dissatisfaction is collected for the service aspects in which a negative Gap value is obtained.

The Analytic Hierarchy Process, AHP (Saaty, 1980, 1996) is a useful methodology to provide information about subjective judgments and has been suggested for measuring service quality. AHP presents several advantages as: full differentiation among importance ratings, seeking consistency in judgments by means of the inconsistency ratio $I R$, easiness to use and so on. It also allows the structuring of complex problems in the form of a hierarchy or a set of integrated levels and can be combined with operations research techniques to handle more difficult problems.

AHP is a multi-criteria decision making (MCDM) method that helps the decision-maker facing a complex problem with multiple conflicting and subjective criteria. However, most of the applications of AHP adopted it to compare two or more services. In a recent paper (Ramanathan \& Karpuzcu, 2010), AHP was proposed to measure service quality by comparing expected and perceived service quality. The authors of this study compared their AHP-based method and SERVQUAL, concluding that users could express their satisfaction and comparisons more easily with the AHP questionnaire than with SERVQUAL.

In view of the above analysis, this study aims at determining the perception of patients towards service quality delivery of public hospitals in Nigeria with the help of analytical hierarchy process (AHP) model to assess and prioritize the generic dimensions or factors for measuring service quality from the perspective of the patients. The specific objectives are to:

i. Identify the factors for measuring service quality.

ii. Examine the perception of patients to the quality of health care provided in hospitals with the aid of analytical hierarchy process.

iii. Prioritize the factors for measuring service quality from the perspective of the patients.

iv. Recommend the best measures to improve quality of hospital service delivery

\section{Literature review}

\subsection{Service quality}

Service quality is defined as "a global judgment or attitude relating to the overall excellence or superiority of the service" (Parasuraman, Zeithaml \& Berry 1988). Service quality is also defined as a customer's overall service quality evaluation by applying a disconfirmation model - the gap between service expectations and performance (Cronin \& Taylor 1992; Potter, Morgan \& Thompson 1994). Perceptions of service quality enable providers of healthcare to detect services and processes in need of improvement. Providers perceive that satisfying patients can save them time and money spent on resolving patient complaints in future (Pakdil \& Haywood, 2005). 
The SERVQUAL instrument is a popular instrument applied in the healthcare industry extensively to measure service quality. Five dimensions (assurance, empathy, reliability, responsiveness and tangibles) are proposed and the magnitude of the differences between customer perceptions and expectations are implemented for measuring perceived service quality (Parasuraman et al., 1988).

- Tangibles: The appearance of physical facilities, equipment, appearance of personnel, and communication materials.

- Reliability: The ability of hospital to perform the promised service dependably and accurately (that is, when something is promised, it is done and provision of services at the time promised).

- Responsiveness: The willingness of hospital's personnel to help customers and provide prompt service.

- Assurance: The knowledge and courtesy of hospital employees and their ability to inspire trust and confidence.

- Empathy: The caring, individualized attention the hospital provides to its customers (that is, employees understand specific needs and employees give personal attention).

\subsection{Patient satisfaction and perceived service quality in healtheare}

Healthcare sector research into patients' perceptions of the dimensions of service quality (perceived service quality) has been limited (Clemes, Ozanne and Laurensen 2001), yet studies seeking to assess the components of the quality of care in health services predominately continue to measure patient satisfaction (Lee, Khong, and Ghista, 2006). There is no consensus on how to best conceptualize the relationship between patient satisfaction and their perceptions of the quality of their healthcare. O'Connor and Shewchuk (2003) emphasized that much of the work on patient satisfaction is based on simple descriptive and correlation analyses with no theoretical framework. They concluded that, with regard to health services, the focus should be on measuring technical and functional (how care is delivered) quality and not patient satisfaction.

A study by Gotlieb Grewal and Brown (1994) on patient discharge, hospital perceived service quality and satisfaction offered evidence of a clear distinction between perceived service quality and patient satisfaction. They found that patient satisfaction mediated the effect of perceived service quality on behavioural intentions, which include adherence to treatment regime and following provider advice. Cleary and Edgman-Levitan (1997) pointed out that satisfaction surveys in the health care sector did not measure quality of care as they did not include important aspects of care items such as being treated with respect and being involved in treatment decisions. In addition, Taylor (1999) highlighted that confusion continued in the sector regarding the differentiation of service quality from satisfaction and reported that some authors, for example Kleinsorge and Koenig (1991), referred to them as synonymous terms. Nevertheless patient satisfaction continues to be measured as a proxy for the patient's assessment of service quality (Turris, 2005).

\subsection{Theoretical framework and model development of analytical hierarchy process (AHP)}

The analytical hierarchy process (AHP) model was innovated by Saaty (1980). The AHP was adopted because it has been successfully applied to solve multi-criteria decision making problems (Saaty, 1980; 2000). This method mixes the opinions and evaluations of expert people and turns a complex decision making system into a hierarchical one. Then the evaluation method is applied by proportional scale so that it could continue its applications by proportional importance of pairwise comparisons between criteria. This method breaks down the complex hierarchical problems from upper level to the lower ones. We can calculate the proportional weight of criteria by using the special vector of 
pairwise comparisons matrix. Therefore, this research uses this method to evaluate the proportional weight of five criteria in measuring the quality of service.

Before using AHP model for this study, we needed to identify the goal (Determine patients perception towards quality of services rendered); the criteria (five generic dimension of service quality), the sub-criteria (physical facilities (PF), employee appearance (EA), equipment (EQ), prompt service (PS), accuracy of medical report (AMR), accuracy of expense report (AER), willingness of administration staff to attend to patients queries (WASPQ), adequate information to patients (AIP), warm and caring attitude(WCA), proficient medical staff (PMF), employees attentions to patient (EAP) employees understanding towards feelings of discomfort (EUFD), affordable service charges(ASC)) and the alternatives (the two public hospitals).

\section{Methodology}

This research work is descriptive and analytical in nature. Information were obtained from the patients that patronize the public hospitals selected in Nigeria in other to assess and rate the various factors of service quality dimension using questionnaire structured in an analytical hierarchy process (AHP) format.

-- zstionnaire was the main instrument used in gathering the required data for the study. The

sstionnaire comprises of two sections, section A contains socio-economic characteristics of the respondents, while section B contains the questions relating to the research objectives of the study. The questionnaire was administered on 200 respondents (patients) by non-probability convenience samplings of patients that patronizes the public hospitals selected in Ogun State.

\section{REFERENCES}

Cleary, P.\& McNeil, B. (1988). Patient satisfaction as an indicator of quality of care. Inquiry, 25, 2536.

Cleary, P. \& Edgman-Levitan, S. (1997). Health care quality: incorporating consumer perspectives. Journal of the American Medical Association., 278(19), 1608-1612.

Clemes, M.D., Ozanne, L.K. \& Laurensen, W.L. (2001). Patients' perceptions of service quality dimensions: an empirical examination of health care in New Zealand. Health Marketing Quarterly, $19(1), 3-22$.

Cronin Jr, J. J., \& Taylor, S. A. (1992). Measuring service quality: A reexamination and extension. The Journal of Marketing, 55-68.

Donabedian, A. ,(1988). The quality of care. How can it be assessed? JAMA; 260: 1743-1748.

Gilbert, F.W., Lumpkin, J.R. \& Dant, R.P. (1992). Adaptation and customer expectations of health care options. Journal of Health Care Management, 12(3), 46-55.

Gotlieb, J.B., Grewal, D. \& Brown, S.W. (1994). Consumer satisfaction and perceived quality: Complimentary or divergent constructs. Journal of Applied Psychology, 79(6), 875-885.

Kleinsorge, I.K. \& Koenig, H.F. (1991). The silent customers: measuring customer satisfaction in nursing homes. Journal of Health Care Marketing, 11( ) 4, 2-13. 
Lee, P.-M., Khong, P. \& Ghista, D.N. (2006). Impact of deficient healthcare service quality. The TQM Magazine, 18(6), 563-571.

Levine, A.S. , Plume, S. K, \& Nelson, E. C., (1997). Transforming patient feedback into strategic actions plans. Qual Manag Health Care; 5: 28-40.

O'Connor, S.J. \& Shewchuk, R. (2003). Commentary - patient satisfaction: what is the point? Health Care Management Review. 28(1), 21-4.

Pakdil, F., \& Harwood, T. N. (2005). Patient satisfaction in a preoperative assessment clinic: An analysis using SERVQUAL dimensions. Total Quality Management \& Business Excellence, 16(1), 1530 .

Parasuraman, A., Zeithami, V.A. \& Berry, L.L. (1985). A conceptual model of service quality and its implications for future research. Journal of Marketing, 49(3), 41-50.

Parasuraman, A., Zeithami, V. A., \& Berry, L. L. (1988). SERVQUAL: A Multiple-Item Scale for measuring consumer perceptions of service quality. Journal of retailing, 64(1), 12-40.

Potter, C., Morgan, P., \& Thompson, A. (1994). Continuous quality improvement in an acute hospital: A report of an action research project in three hospital departments. International Journal of Health Care Quality Assurance, 7(1), 4-29.

Ramanathan, R., \& Karpuzcu H. (2010). Comparing perceived and expected service using an AHP model: An application to measure service quality of a company engaged in pharmaceutical distribution. OPSEARCH

Ramsaran-Fowdar, R. R. (2008). The relative importance of service dimensions in a healthcare setting. International Journal of Health Care Quality Assurance, 21(1), 104-124.

Saaty, T. L. (1980). The analytic hierarchy process: planning, priority setting. New York: McGraw Hill International Book Co.

Saaty, T.L. (1996). The Fundamentals of Decision Making and Priority Theory with the Analytic Hierarchy Process, Vol. IV of the Analytic Hierarchy Process Series. Pittsburgh, PA: RWS Publications.

Saaty, T. L. (2000). Fundamentals of Decision Making and Priority Theory with Analytical Hierarchy Process. Pittsburgh, PA: RWS Publications.

Sitzia J, Wood N. (1997). Patient satisfaction: A review of issues and concepts. Soc Sci Med;45: 1829-1843.

Turris, S.A. (2005). Unpacking the concept of patient satisfaction: a feminist analysis. Journal of Advanced Nursing, 50(3), 293-298. 